\title{
O grupo e seus limites
}

\author{
Gilberto Velho
}

Nos últimos meses de 1990 registrou-se no Rio de Janeiro uma série de assassinatos que despertou um clamor público talvez inédito. Foram realizadas manifestações e passeatas com a presença de políticos de vários partidos. $\mathrm{Na}$ imprensa escrita abriu-se um espaço para grandes reportagens e artigos sobre o assunto. No rádio e na TV produziram-se diversos programas com entrevistas e debates. Velhos crimes ainda impunes saíram do esquecimento público. Organizou-se, com relativa rapidez, um movimento social de alguma complexidade. O ineditismo de fato é aparente. Sem considerar outros episódios de alguma repercussão(1), em 1963 houve um assassinato no Rio de Janeiro com características sociologicamente próximas que teve um impacto de amplitude comparável. Também, naquela época, a imprensa abriu um espaço, talvez ainda maior, com grande destaque para o crime. A vítima era o estudante Odilo Costa Neto, filho de família de prestígio social elevado. Seu pai era destacado jornalista e intelectual respeitado e querido. As circunstâncias do crime configuravam uma situação de grande dramaticidade. Odilo morreu defendendo sua namorada em um assalto à mão armada perpetrado por um adolescente negro. Ao lado da violência absurda, da denúncia da insegurança que começava a se espraiar nas ruas da cidade houve, por parte da família e amigos de Odilo, um claro enunciamento da dimensão social do crime $^{(2)}$. Ou seja: o criminoso - menor, pobre e negro - era também vítima. Na ocasião foi desencadeada uma cruzada moral que entre algumas conseqüências produziu uma reforma do antigo SAM (Serviço de Assistência ao Menor) que veio dar origem à FUNABEM (Fundação Nacional do BemEstar do Menor).

As vítimas de 1990 eram, na sua maioria, também membros de famílias e camadas médias bem relacionadas. Eram jovens filhos de profissionais liberais. Num curto espaço de tempo sucederam-se os episódios que configuravam um quadro de grande insegurança, explicitando a vulnerabilidade das pessoas que saíam de casa para programas inocentes como ir à praia, tomar um chope num bar conhecido, levar a namorada ao cinema. Políticos, intelectuais e familiares das vítimas, em diferentes tipos de pronunciamentos, denunciaram as condições gerais da cidade e da sociedade procurando precisar o significado dos crimes. Portanto nos dois episódios, de 1963 e 1990, as vítimas foram jovens de camadas médias cujas famílias tinham prestígio social, dispunham de acesso à imprensa e participavam de redes sociais com forte potencial de mobilização. Há que registrar que em 1990 um dos assassinados era pobre e negro mas as circunstâncias de sua morte o aproximaram dramaticamente dos outros. De qualquer forma todos os crimes ocorreram na zona sul da cidade, em áreas e locais freqüentados por elites e grupos mais abonados.
1 Há que destacar o importante movimento associado aos "crimes contra mulheres" que nos últimos dez anos mulheres" que nos últimos dez anos defesa dos direitos femininos.

2 Esses fatos estăo fartamente documentados nos jornais e revistas da época.

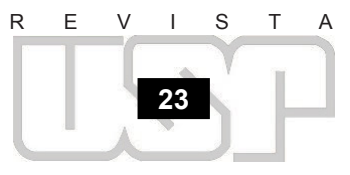




\section{II}

Em 1948, o sociólogo americano Everett C. Hughes proferiu uma conferência na McGill University, em Montreal, depois de uma viagem à Alemanha. Transformou-se, anos mais tarde, no artigo célebre "Good People and Dirty Work" (1962) $)^{(3)}$.

Hughes visitou a Alemanha pós-guerra conversando e entrevistando pessoas sobre o nazismo, campos de concentração, violência, racismo, etc. No seu artigo procura entender como pessoas normais, "good people", conviveram com as atrocidades perpetradas durante cerca de doze anos. Em resumo, o autor mostra que existia uma cumplicidade entre essas "boas pessoas" e aquelas que faziam o "trabalho sujo" de prender, torturar e matar judeus, comunistas, ciganos, inimigos políticos do regime em geral, homossexuais e qualquer tipo de pessoa que pudesse ser considerada perigosa ou inadequada. Os SS eram basicamente o corpo de especialistas do regime encarregados de "despoluir" a sociedade. Eram, muitas vezes, desequilibrados e sádicos. Personalidades violentas, lindeiras da anormalidade ou mesmo patológicas compunham a maior parte do quadro da SS, segundo diferentes intérpretes e analistas. Assim, as "boas pessoas" não precisavam sujar suas mão com o sangue das vítimas pois existia esse corpo de devotados especialistas pronto e disposto a qualquer coisa. Hughes não diz que as "good people" desejassem o extermínio dos judeus ou de qualquer outro grupo. Sabiam algo sobre os campos de concentração, mas de forma fragmentada e incompleta. Os que sabiam mais, geralmente procuravam saber, e esta atitude já estava associada a uma postura de crítica e oposição ao regime. Em geral judeus, ciganos, comunistas, etc. eram encarados como estranhos, distantes e eventualmente perigosos. Como diz um dos entrevistados de Hughes "algo precisava ser feito". Entre o "algo" e o extermínio em massa estava um terreno nebuloso, vago e indefinido que as "boas pessoas" faziam questão de desconhecer.

Hughes examina a Alemanha nazista como um "caso limite". Em toda sociedade de certa complexidade existe um "dirty work" a ser feito. Para isso existem especialistas que se encarregam da tarefa. Quanto ao objeto - vítimas - deste trabalho, variando de sociedade para sociedade, sempre corresponde a algum tipo de out-group. Como diz Hughes: "Toda sociedade de um certo tamanho tem in-groups e out-groups. Só existe um in-group porque existem out-groups... cada um de nós é o centro de uma rede de in e out-groups... A distinção entre in e out pode ser traçada de várias maneiras e nada é mais importante, tanto para o estudioso da sociedade como para o educador, do que descobrir como essas fronteiras são estabelecidas e como podem ser alteradas de modo mais justo e correto"(4).

\section{III}

Voltamos aos assassinatos no Rio de Janeiro de 1963 e 1990. Os chamados "crimes comuns" não são fenômenos isolados. No Brasil, nos últimos cinqüenta anos, tanto no Estado Novo como no Regime Militar que se instalou em 1964, tivemos períodos de implacável perseguição política com prisões arbitrárias, seqüestros, torturas e assassinatos. Esses "crimes políticos" foram basicamente cometidos por órgãos de segurança que eram a nossa versão tropical dos SS nazistas. Aqui como lá as "boas pessoas" resistiam a admitir a existência de tais truculências. A partir de 1964, durante uns vinte anos, a sociedade brasileira viveu sob um regime em que esses episódios aconteciam em escala assustadora embora diferente da Alemanha nazista. Os vizinhos Argentina, Uruguai, Paraguai e Chile passaram, como sabemos, por situação semelhante. O complexo processo de abertura no Brasil, com as sístoles e diástoles do general Golberi, fez com que fosse considerado sábio e prudente não apurar os crimes e atrocidades. A descoberta de cemitérios clandestinos reaviva a memória e impede o esquecimento. De qualquer forma, com a eleição de Tancredo Neves, com Sarney, a "Nova República" e com as eleições diretas para presidente da República procurou-se marcar um distanciamento em relação ao finado Regime Militar. Supōe-se que haja liberdade política e que agora estejam distantes os dias do DOI-CODI e dos nossos SS. Mas e os "crimes comuns"? O próprio termo "comum" já mereceria análise adequada. 
É diff́cil em uma época de relativa liberdade de imprensa e com uma crise social aguda não perceber a gravidade dos problemas da grande maioria da população brasileira. A violência dos assassinatos é uma dimensão desse quadro geral de deterioração acelerada. Quem é assassinado e qual o significado dessies crimes? As vítimas aqui citadas, de 1963 e 1990, eram em geral, como já foi dito, filhos de famflias com prestígio, educação e recursos básicos. A partir de suas mortes e sacrifício, o clamor e os protestos foram importantes e meritórios com sua vigorosa denúncia da impunidade, da violência gratuita e da injustiça em geral. Mas talvez o mais importante em termos sociológicos e éticos seja a revisão, nos termos de Hughes, de nossa visão de in e out-groups. As mortes de jovens de camadas médias e suas circunstâncias são a ponta do iceberg da violência onipresente no cotidiano da grande maioria da população brasileira. As camadas pobres, os moradores de favelas, da periferia e dos subúrbios das cidades brasileiras estão sujeitos permanentemente a todos os tipos de arbitrariedade. Os assaltos, as batidas policiais, a ação dos "esquadrōes da morte" somam-se às dificuldades de trabalho, moradia, transporte, saúde, etc. que constituem as condições de existência dessa população. As nossas "boas pessoas", de um modo geral, só são sacudidas quando ocorre uma tragédia dentro de seu limitado in-group. É fascinante em termos sociológicos e chocante em termos éticos ver pessoas se deslocando dentro de uma sociedade injusta e violenta, anestesiadas diante da misćria, sofrimento e violência que afligem permanentemente os out-groups, no caso, a maioria esmagadora da população. No Brasil, no Rio de Janeiro particularmente, com exceção de algumas poucas áreas como certos condomínios fechados, não parece viável a metafórica redoma de vidro que faz com que em sociedades mais guetificadas as elites possam viver boa parte do seu tempo ignorando as mazelas do povo. No entanto os mecanismos socioculturais de distanciamento e hierarquização possibilitam a existência e manutenção de sutilíssimos mapas de navegação social que permitem, se não uma redoma, talvez uma espécie de capa ou invólucro protetor de insensibilização. Assim, nos aproximamos da Alemanha nazista com seus "good people" e "dirty work", analisados por Hughes. As ações dos SS, do DOI-CODI, dos "esquadrões da morte", dos corpos de segurança privados desempenham essa fusão de "sanear" a sociedade dos excessos dos şubversivos, das minorias e dos pobres. A consciência das "boas pessoas" fica protegida porque não se envolvem diretamente com a poluição social. A maioria só se abala quando um parente ou uma pessoa muito próxima vai para o campo de concentração ou é seqüestrada, presa, torturada e/ou assassinada. Os exemplos internacionais ou brasileiros são numerosos e gritantes.

Os épisódios de 1963 e 1990 no Rio de Janeiro ilustram dramaticamente essa reflexão. $\mathrm{O}$ universo das camadas médias superiores e das elites vem ali experimentando uma crescente insegurança. Furtos, roubos e assaltos já fazem parte do dia-a-dia. Isso tem levado a uma reavaliação de estilo de vida com novas estratégias e mudança de hábitos $^{(5)}$. No terreno das atitudes e representaçōes são poucos aqueles que efetuam uma crítica das condições gerais de existência da sociedade. As famńlias das vítimas de 1963 e 1990 realizaram esse movimento e esforço de denúncia. No entanto, na grande maiória dos depoimentos que tenho colhido na minha pesquisa nos últimos dois anos, ao focalizarem a violência na cidade as pessoas desses estratos superiores tendem a reforçar uma política repressiva ${ }^{(6)}$. Acreditam que os órgãos de segurança não são eficientes e que o efetivo policial deve ser aumentado. Vários falam nos assaltantes e criminosos como inimigos que devem ser eliminados, custe o que custar. A maioria é favorável à pena de morte e regimes mais rigorosos no sistema penitenciário. Uma minoria estabelece relação entre a violência e os problemas de pobreza e distribuição de renda. Diversos dão explicações de natureza étnica-racial, proferindo julgamentos sobre a inferioridade de negros, mulatos, nordestinos ou brasileiros em geral. Basicamente estabelecem uma relação de exclusão no tocante ao povo como um todo. Não elaboram nenhuma identificação com as vítimas da violência a não ser aquelas de seu círculo imediato, estabelecendo limites rígidos entre o seu grupo e o mundo de fora, como:

"Essa gente vive se matando nas favelas. Agora estão vindo para cima de nós. O Governo e a Polícia não estão controlando a cidade. É uma vergonha, não dá mais para sair de casa. Por isso sou a favor da pena de morte. É o único jeito de acabar com isso".

(Engenheiro, 42 anos, morador do Leblon, RJ)
5 Gilberto Velho. "Destino, campo de possibilidades e províncias de significado: notas sobre a violéncia", in Comunicaçăo, no 16. PPGAS - Museu Nacional - UFRJ, 1989.

6 Estudo comparativo de estilos de vida metropolitanos. Convênio FINEP $\mathrm{n}^{\circ}$ 4.3.88.0513.00/dc 2̧̧ăo FORD $n^{\circ} 840$ 0709-A. Até agora disponho de cerca de cinqüenta entrevistas realizadas. 
Neste depoimento e em outros há uma queixa de que o "dirty work" não está sendo feito a contento. Alguns chegam a falar em se armar para fazer justiça. Mas principalmente tendem a insistir na necessidade de tornar o aparelho repressivo mais eficiente $e$ na necessidade de confinar as populações de baixa renda.

"Tem que remover as favelas. O Lacerda tinha toda razão. Não dá para conviver com essa gente. As ruas estão cheias de mendigos e de pivetes. Tem que acabar com isso. A cidade tem que ser melhor organizada. $O$ que estraga o Rio é essa mistura".

(Advogado, 54 anos, morador de Copacabana)

Assim aqui temos um discurso e uma atitude que servem de sustentação para as medidas repressivas contra a população de baixa renda, o grande out-group. Diferentemente, os familiares e amigos de Odilo, em 1963, e o movimento de 1990 procuraram esboçar uma crítica geral da sociedade para explicar os crimes, ampliando assim o campo de identificação e de alianças. Tentaram estabelecer pontes entre os diferentes tipos de vítima, independentemente do seu grupo social de origem, como:

"Perdemos um parente, uma pessoa querida. Sabemos que isso tem acontecido com muita gente. Principalmente com o povo mais pobre. É hora de tentar mudar isso, acabar com a impunidade. É uma sociedade injusta e cruel".

(Jornalista, 35 anos, morador de Copacabana)

Essas idéias representam uma vertente do universo das camadas médias com uma postura mais reformista. $O$ sucesso de suas iniciativas é discutível e problemático mas expressa uma visão diferente do rígido mapa social dos depoimentos anteriormente citados. Sugiro que estamos lidando com um discurso e visão de mundo complexos, nãohomogêneos. Nos depoimentos constantemente há matizes e meio-tons. Assim, em 1990, aparece com vigor em vários momentos a preocupação de castigar e punir os assassinos nem sempre associada à idéia de reforma e justiça social. São, essencialmente, dois modos de definir e lidar com o "outro". Enquanto em um caso o in-group é marcadamente restrito e fechado, no segundo há uma inclusão de um segmento maior da sociedade e/ou humanidade. Este está associado a um projeto de mudança e reforma enquanto o primeiro vincula-se à manutenção das fronteiras sociais e de um modelo em que o in-group está permanentemente ameaçado pelo stranger e pelo outsider ${ }^{(7)}$. São distintas possibilidades de construção social da realidade com repercussões em todas as esteras e domínios. Em termos estritamente políticos creio que ainda se pode falar, apesar de protestos, em "esquerda" e "direita" como referências de orientação básicas. $\mathrm{Na}$ prática os depoimentos oscilam entre os dois pólos da reforma social e da repressão. $O$ discurso da reforma pode estar combinado com a defesa de medidas coercitivas de natureza policial, como:

"Sem melhor distribuição de renda não há saída. Com esse desemprego e com esse salário mínimo é até surpreendente que não haja maior violência. Agora, é claro que não pode dar moleza para os bandidos que estão por aí, ligados aos bicheiros e traficantes. A polícia tem que ser reformada e reaparelhada para poder atuar. Essa corrupção generalizada contamina tudo".

(Economista, 46 anos, morador do Jardim Botânico)

7 Ver Alfred Schultz, Collected Papers, Haia, Martins Nijhoff, vol. 2, 1970 Howard S. Becker, Outsiders, Studies in the Sociology of Deviance. New York, The Free Press, 1966.

Como vimos os tipos "puros" de "reformista" e "repressivo" podem até ser encontrados em certos contextos e momentos. Indivíduos específicos desempenham esses papéis com toda a plenitude. Creio que pode ser útil pensar em termos de um repertório cultural e ideológico que é acionado por este universo de modo diferenciado. Retornando mais uma vez a Hughes, a possibilidade de repensar e redesenhar os limites entre o in e os out-groups é uma questão sociologicamente fascinante e crucial em termos políticos e éticos. Quanto maior a ampliação dessas fronteiras e mais abrangente a percepção do universo de referência, melhores serão as possibilidades de um projeto social efetivamente democrático. As fronteiras sociológicas não são definitivas e nem devem ser congeladas, seja pelo pesquisador seja pela ação política. Ao se entender a sociedade como um complexo processo de interação e negociação da realidade, abre-se a possibilidade de compreender e estimular mudanças política e eticamente desejáveis. 